\title{
IUFOST2006/570 Mesoscale simulation of soft condensed matter as foods with Lattice Boltzmann
}

\author{
R. Van Der Sman, S. Van Der Graaf, J. Kromkamp and G. Brans \\ Wageningen University, P.O. Box 8129, 6700 Wageningen, Netherlands \\ ruud.vandersman@wur.nl
}

Soft condensed matter (SCM) is quite a novel branch of physics, generating a wealth of knowledge that will help food scientists construct the rational design of complex food materials for new food products. SCM is a complex fluid consisting of mesoscopic structures dispersed in a liquid.

The last years food scientists have recognized the potential of SCM to create, and facilitate, new food structures and processes (Mezzenga, 2005). Important progress in SCM is made by mesoscopic simulation methods, which are able to solve the evolution of the mesoscopic structures via hydrodynamics. Five years ago we have recognized the potential of mesoscopic simulation methods, and have applied it successfully in several research projects on food structuring.

In our research we have applied the mesoscopic method named Lattice Boltzmann, to 1) emulsion droplet formation in microfluidic devices (van der Graaf 2006, van der Sman 2006), and 2) microfiltration and fractionation of dairy suspensions with microfluidic devices (i.e. microsieve) (Kromkamp,2005a \& 2006) (Brans, 2006). Simulation results as compared with experimental data will be presented. With respect to microfiltration the coupling to macroscopic model will be discussed (Kromkamp, 2005b). The macroscopic model is also implemented in Lattice Boltzmann. This provides a more general view how to build a multiscale modeling approach for modeling processing of soft condensed matter as foods.

References o R. Mezzenga, P. Schurtenberger, A. Burbidge, and M. Michel. Understanding foods as soft materials Nature Materials 4, 729740 (2005). o S. van der Graaf, T. Nisisako, C.G.P.H. Schroën, R.G.M. van der Sman, R.M. Boom. Lattice Boltzmann simulations of droplet formation in a T-shaped microchannel. Accepted for Langmuir (2006). o Shear-induced self-diffusion and microstructure in non-Brownian suspensions at non-zero Reynolds numbers. J. Kromkamp, D.T.M. van den Ende, D. Khandai, R.G.M. van der Sman, R.M. Boom. J. Fluid Mech 529: 253-278 (2005a). o Kromkamp, J., A. Bastiaanse, J. Swarts, G. Brans, R.G.M. van der Sman, and R.M. Boom, "A suspension flow model for hydrodynamics and concentration polarisation in crossflow microfiltration", J. Membr. Sci., 253(1-2): 67-79 (2005b). o J. Kromkamp, D.T.M. van den Ende, D. Kandhai, R.G.M. van der Sman, R.M. Boom. Lattice Boltzmann simulation of 2D and 3D non-Brownian suspensions in Couette flow. Chem. Eng. Sci. 61 (2): 858-873 (2006). o G. Brans, R.G.M. van der Sman, C.G.P.H. Schroën, R.M. Boom. Optimization of the membrane and pore geometry for micromachined membranes. Accepted for J. Membr. Sci. (2006). o R.G.M. van der Sman, and S. van der Graaf. Lattice Diffuse interface model for surfactant adsorption onto evolving interface. accepted for Rheologica Acta (2006). 